\title{
Temporal and multiple scale spatial variation in juvenile and adult abundance of the brown alga Ascophyllum nodosum
}

\author{
Per Åberg ${ }^{*}$, Henrik Pavia \\ Department of Marine Botany, Göteborg University, Carl Skottsbergs Gata 22, S-413 19 Göteborg, Sweden
}

\begin{abstract}
Observation of spatial and temporal variation in the distribution and abundance of organisms is often the starting point from which questions and hypotheses about ecological processes arise This study was designed to investigate spatial variability in abundance of macrorecruits and adults of the brown alga Ascophyllum nodosum using hierarchical sampling programs. Five spatial scales ranging from $10^{-1}$ to $10^{6} \mathrm{~m}$ were used, where the largest scale was represented by the distance between 2 areas, Tjärnö on the Swedish west coast and the Isle of Man in the Irish Sea. Temporal variation was investigated separately over 3 spatial scales as comparisons among the years from 1992 to 1995. Significant variation in abundance of $1.5 \mathrm{yr}$ old juveniles was found on 2 spatial scales, 0.1 to $1.5 \mathrm{~m}$ and 2 to $30 \mathrm{~m}$. A large variation among replicates suggested substantial variation on a smaller scale $(<0.15 \mathrm{~m})$. There was no significant variation in the abundance of juveniles among years as suggested by earlier studies. The abundance of the adult population varied between areas but not on smaller spatial scales. There was a significant variation in the abundance of the adult population among years. The potential egg production in female individuals was also investigated as a means of relating the abundance of juveniles to fertility estimates. The number of eggs per conceptacle and the number of conceptacles per receptacle did not vary significantly among individuals and the mean number of eggs per receptacle was estimated to be $7 \times 10^{4}$ The potential egg production was estimated to be $2.5 \times$ $10^{9}$ eggs $\mathrm{m}^{-2}$, a value much higher than previously reported for fucoids. Given the mean value of 40 juveniles $\mathrm{m}^{-2}$, the transition probability from egg to juvenile was estimated to be $2 \times 10^{-8}$
\end{abstract}

KEY WORDS: Ascophyllum nodosum - Spatial variation - Temporal variation - Hierarchical sampling Juvenile abundance - Egg production - Seaweed

\section{INTRODUCTION}

It is well known that temporal and spatial variation in characters of plant and animal individuals, populations, communities and their environment is important and has a great impact on our understanding of patterns in nature. Levin (1992) argued that the understanding of scales of space and time is the fundamental conceptual problem in ecology, if not in all science. Observation of patterns on 1 or several spatial and/or temporal scales is often an important starting point of the scientific process from which questions and hy-

\footnotetext{
•E-mail: per.aberg@marbot.gu.se
}

potheses arise (Underwood 1991, Levin 1992). Observations may be of several kinds, for instance qualitative observations such as walking on the shore and noticing interesting things, which may be a first step that is later developed into well-designed observations where hypotheses are tested. In such instances the observations can be regarded as an experiment (Underwood 1991). However, it is important to distinguish such observational experiments from controlled manipulations. The former can be used to test hypotheses of patterns, while the latter have the potential to test hypotheses about mechanisms and casual relationships (Underwood \& Denley 1984, Underwood 1985). Since patterns may be different at different spatial scales, observational experiments of patterns must be 
designed to reveal this. One way to do this is to use hierarchical sampling programs that provide an estimate of the contribution of each scale to the total variation among samples within the largest scale of comparison (Morrisey et al. 1992) using nested analysis of variance (Underwood 1997).

The aim of this study was to investigate the spatial and temporal variation in the abundance of macrorecruits ( $>1 \mathrm{~mm}$; cf. Ang 1991) of the brown alga Ascophyllum nodosum (L.) Le Jol. The general hypothesis was that variation should be different at different spatial scales. We investigated 5 spatial scales ranging from $10^{-1}$ to $10^{6} \mathrm{~m}$. We also studied temporal variation among years in combination with variation among 3 spatial scales. These studies were done in the mid intertidal zone on shores on the Isle of Man and in the middle of the $A$. nodosum zone on almost atidal shores on the Swedish west coast. In a third experiment we tested the hypothesis that the recruitment of $A$. nodosum may be more common higher in the intertidal. This has been suggested by qualitative observations in populations in Maine, USA (A. Mathieson pers. comm. in Lazo et al. 1994) and on the Isle of Man (Jenkins 1995, S. Hawkins pers. comm.). Although patchiness is a well-known phenomenon of seaweeds, the findings are usually from qualitative observations.

Observational experiments on multiple scales are rare in ecological research on macroalgae, but such studies may be of great importance. For example, in an observational experiment on spatial variation of the polyphenolic content in Ascophyllum nodosum it was shown that significant variation existed on 2 scales, 1 to $50 \mathrm{~m}$ and 400 to $1000 \mathrm{~m}$ (Pavia \& Aberg 1996). Consequently, studies of large scale variation in polyphenolics based on a few samples from a single site per area (e.g Rönnberg \& Ruokolahti 1986, Tuomi et al, 1989. Van Alstyne \& Paul 1990, Steinberg et al. 1991, Targett et al. 1992) should be interpreted with caution. Several papers with controlled experiments have studied factors that regulate the survival of fucoid microrecruits (Chapman 1995 and references therein), but little is known about the variation in their abundance on multiple spatial scales. For the survival of microrecruits of $A$. nodosum, and consequently the transition to macrorecruits, several factors have been shown to reduce recruitment, e.g. wave action (Vadas et al. 1990), canopy of adult plants (Vadas et al. 1992, Jenkins 1995) and grazing (Lazo et al. 1994). Besides our interest in spatial and temporal variation in macrorecruits, the present study was also done to investigate the variation in the fertility of A. nodosum. We measured the potential egg production and the spatial and temporal variation in abundance and size of adult plants. These findings, in combination with earlier results, provide fertility measures for demographical budgets.

\section{MATERIALS AND METHODS}

The study covered 2 areas: (1) the islands on the northern part of the Swedish west coast, close to Tjärnö Marime Biological Laboratory $\left(58^{\circ} 54^{\prime} \mathrm{N}, 11^{\circ} 07^{\prime} \mathrm{E}\right)$ and (2) the shores at Langness, Derbyhaven, and St Michaels Island on the Isle of Man in the Irish Sea $154^{\circ}$ $\left.05^{\prime} \mathrm{N}, 4^{\circ} 37^{\prime} \mathrm{W}\right)$. These 2 areas are hereafter referred to as Tjärno and the Isle of Man. In these areas the general abiotic conditions are very different. The Tjärnö area is almost atidal (tidal range $0.3 \mathrm{~m}$ ), but larger irregular changes from about $0.5 \mathrm{~m}$ below to $1.5 \mathrm{~m}$ above the mean water level occur due to changes in air pressure and winds (Johannesson 1989). Large fluctuations in salinity are also common in this area and the mean salinity is $24 \%$. In about $25 \%$ of the winters there are periods when ice covers the sea. The ice cover has been found to be an important source of mortality for Ascophyllum nodosum and the environment can be described as stochastically varying (Aberg 1992a, b). At the Isle of Man the conditions are much more stable, with a tidal range of about $7 \mathrm{~m}$, stable salinity (mean $34 \%$ ), except around local freshwater outlets, and no formation of ice. At the Isle of Man the vertical distribution of $A$. nodosum is large, 2 to $3 \mathrm{~m}$ in the mid intertidal zone on sheltered shores, compared to 0.1 to $0.5 \mathrm{~m}$ below the mean water level at Tjärnö. Thus, the width of the $A$. nodosum belts at the Isle of Man may reach $100 \mathrm{~m}$ on shores with gentle slopes, but at Tjärnö belt width is u.sually less than $0.5 \mathrm{~m}$, and rarely exceeds $2 \mathrm{~m}$. A. nodosum is not harvested in the 2 areas.

In this study we defined a juvenile individual to be $<1 \mathrm{~cm}$ long The growth of Ascophyllum nodosum recruits during the first year has been estimated to be about 1 to $2 \mathrm{~mm}$ (Sundene 1973, Lazo et al. 1994), but may be up to $1 \mathrm{~cm}$ (Peckol et al. 1988). Since our study was done in September to October of each year we assumed that the juveniles were 1.5 yr old. We further restricted our study to sheltered shores with well-developed $A$. nodosum beds. That is, all counts of juveniles were done at sites where adult individuals were common.

Spatial variation in juvenile abundance. In this experiment we investigated the spatial variation in juvenile abundance on 5 spatial scales with a hierarchical sampling design. It included 2 areas $\left(10^{6} \mathrm{~m}\right.$ apart), 10 sites within each area (200 to $6000 \mathrm{~m}$ apart), 5 plots (each $2 \mathrm{~m}$ long) within each site (at a distance 2 to $30 \mathrm{~m}$ apart), and 4 squares within each plot with a size of $0.25 \times 0.25 \mathrm{~m}$ (distance between squares 0.1 to $1.5 \mathrm{~m}$ ). In each square, 6 replicate readings of the number of juveniles was done in $0.05 \times 0.05 \mathrm{~m}$ squares (distance between replicates 0.05 to $0.15 \mathrm{~m}$ ), giving a total sample size of 2400 . The experiment was done at Tjärnö in the middle of September 1995 and in the beginning of October 1995 at the Isle of Man. 
The effect of the height of the shore on the abundance of juveniles was investigated at the Isle of Man in the beginning of October 1995. This experiment was not done at Tjärnö since shore height is not a relevant factor in the narrow Ascophyllum nodosum zone on the Swedish west coast. Within the natural limits of the A. nodosum zone we classified 3 heights, high, medium, and low shore. Three spatial scales, site, plot, and square, on the same scale as above, were also used in the study. Since all 3 heights were investigated at all 6 sites these factors are orthogonal. At each site and shore height, 3 plots were placed and within them 3 squares. Six replicate readings were done in each square, giving a total sample size of 972 .

Temporal and spatial variation in abundance of plants. These data are extracted from a larger study of the demography of Ascophyllum nodosum at the Isle of Man and Tjärnö. The study started in the autumn of 1992 and ended in the autumn of 1995. In each area, 3 sites were chosen at random, and within each site 14 to 17 squares were placed at random, at the beginning of the study. In each square, 5 large individuals were tagged ( $>5 \mathrm{~g}$ dry mass; cf. classes 2 to 5 in $\AA$ berg 1990) and 3 small $<5$ g dry mass; mainly class 1 in Åberg 1990) individuals were mapped and followed. With very few exceptions, this division into small and large plants separates nonreproductive and reproductive plants (A berg 1990). It is, however, not a division into juveniles and adults since small plants may be adults that have been broken (Åberg 1992a). The length and circumference of these tagged and mapped individuals was measured and their size estimated with the method described in Åberg (1990). Further, all large and small individuals within the square were counted and from 1993 to 1995 all new individuals within the squares were counted. To avoid dependent samples we have only used data from 5 or 6 randomly chosen squares at each area, site and time. Five squares were used when 4 yr of data were available and 6 squares when 3 yr of data were available

The variables analysed were: the number of new individuals within squares, the density of small, large and total individuals, and the length and estimated dry mass of large (reproductive) individuals. For estimates of abundance, 2 spatial scales were used, areas and sites within areas. For the length and dry mass of large individuals we also analysed the variation between squares within sites. The spatial scales were slightly different from those used to study variation in juvenile abundance, the distance between sites varied from 400 to $3000 \mathrm{~m}$ and the distance between squares within sites from 1 to $80 \mathrm{~m}$.

Potential egg production. The variation in the number of eggs per conceptacle between receptacles within and among individuals was analysed with a hierarchi- cal design. Ascophyllum nodosum reproduce during a short period in the spring. In Sweden this period is often $<2$ wk. The starting date for reproduction varies among years, but in Sweden it usually starts in the first $2 \mathrm{wk}$ of May (authors' pers. obs.). Just prior to gamete release, 10 individuals were sampled at random from several sites at Tjärnö. From each individual, 3 receptacles were taken and the total number of eggs in 5 conceptacles on each receptacle were counted, giving a total sample size of 150 . First, the wet mass of each receptacle was estimated and the total number of conceptacles per receptacle counted. The conceptacles were then carefully taken from the receptacle with a forceps and gently squashed between 2 microslides. The number of oogonia was counted and multiplied by 4 (eggs per oogonium) to get the number of eggs per conceptacle. The total number of eggs produced by each receptacle was estimated as the mean number of eggs per conceptacle times the number of conceptacles per receptacle.

Statistical analyses. Spatial variability was analysed with hierarchical analysis of variance (ANOVA). The 2 areas were chosen and were consequently considered as fixed factors. We also considered time to be a fixed factor since we investigated 4 successive years. The factor height on shore was chosen to represent 3 classes and also considered as fixed. Sites, plots, and squares were chosen using random number tables, with the restriction that they should not exceed the limits of the spatial scales. Experiments including factors such as time and height on shore were analysed with ANOVAs with both orthogonal and nested factors. The assumption of homogeneity of variances in the ANOVA was analysed with Cochran's C-test (Winer et al. 1991). Data were transformed if variances were significantly heterogeneous. Data on dry mass of large individuals was log-transformed. Counts of individuals were first square-root transformed. If not successful in reducing heterogeneity, data were raised to a smaller power. Multiple mean comparisons were made with the Student-Newman-Keuls (SNK) procedure as described in Underwood (1997) and variance components calculated as described in Winer et al. (1991) and Underwood (1997).

\section{RESULTS}

\section{Spatial variation in abundance of juveniles}

The number of juveniles smaller than $1 \mathrm{~cm}$ was not significantly different between the 2 areas (Table 1) and the overall mean was 40 juveniles $\mathrm{m}^{-2}$. No significant difference between sites within areas was found, but on the 2 smallest spatial scales (plots within sites and squares within plots) significant differences 
Table 1. Nested ANOVA of the number of juveniles per unit area. Data $x^{1 / 4}$ transformed to meet assumption of homogeneity of variances

\begin{tabular}{|lrccccc|}
\hline Source & df & MS & $F$ & $p$ & $\begin{array}{c}\text { Variance } \\
\text { component }\end{array}$ \\
\hline Area & 1 & 0.017 & 0.09 & $>0.75$ & 0 \\
Site (Area) & 18 & 0.183 & 1.39 & $>0.15$ & 0.0004 \\
$\begin{array}{l}\text { Plot (Site, Area) } \\
\text { Square (Plot, Site, } \\
\text { Area) }\end{array}$ & 80 & 0.132 & 1.70 & $<0.001$ & 0.0022 \\
Residual & 2000 & 0.078 & 1.51 & $<0.0001$ & 0.0044 \\
& df & $C$ & & & 0.0511 \\
& & & & & & \\
\hline Cochran's C-test & 400,5 & 0.036 & & $>0.05$ & \\
\hline
\end{tabular}

occurred (Table 1, Fig. 1). Furthermore, the variance component for the residual was $88 \%$ of the total variance, indicating large variation between replicates within squares (Table 1).

\section{Effect of shore height on abundance of juveniles}

Significant differences in the number of macrorecruits at different heights on the shore were found (Table 2), and the SNK test showed that there were more juveniles high on the shore $\left(46 \mathrm{~m}^{-2}\right)$ than at medium $\left(15 \mathrm{~m}^{-2}\right)$ and low $\left(4 \mathrm{~m}^{-2}\right)$ sites on the shore (Fig. 2). Significant differences were also found between squares within height on shore, site, and plot, and this variation is in accordance with the first experiment.

\section{Temporal and spatial variation in abundance of plants}

There was no significant temporal variation in the abundance of new macrorecruits (Table 3 ). The overall

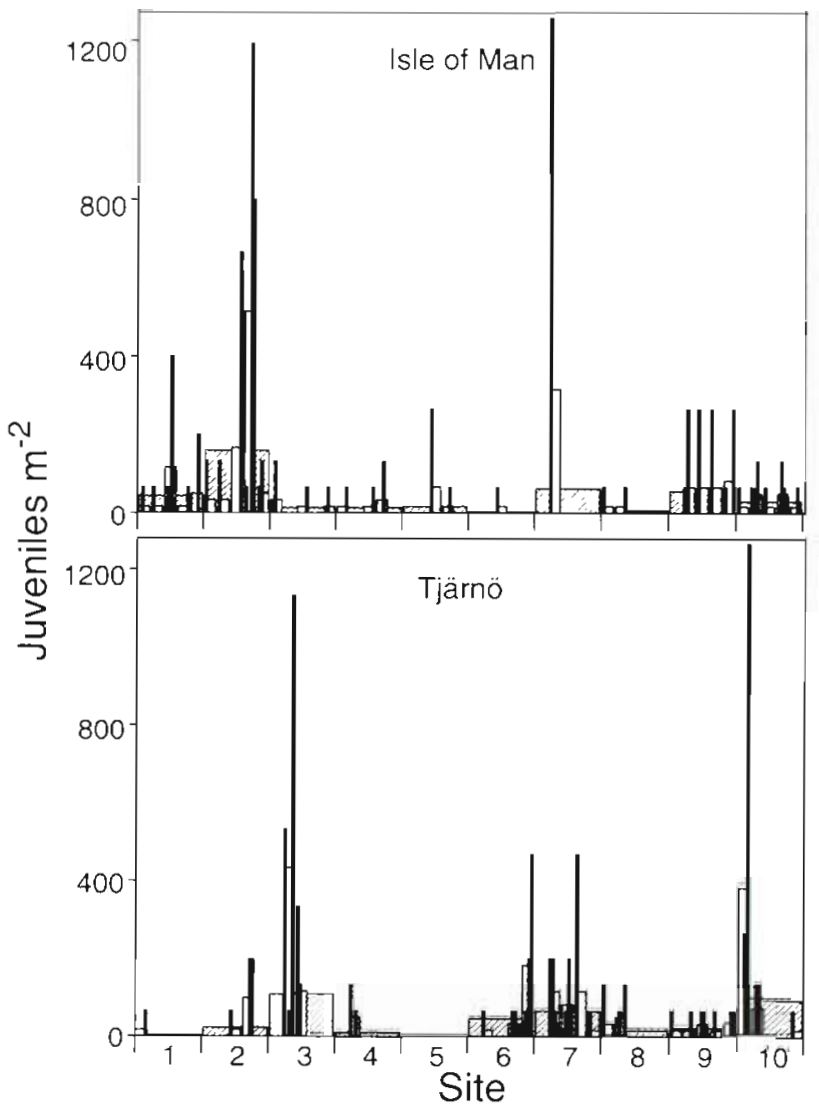

Fig. 1. Ascophyllum nodosum. Mean number of juveniles $\mathrm{m}^{-2}$ at different sites within areas (striped columns), plots within sites (open columns), and squares within plots (black columns)

mean number of new recruits was $13 \mathrm{~m}^{-2}$. Post hoc pooling of the non significant interaction term Year $x$ Site (Area) (as described in Underwood 1997) did not reveal any significant differences in abundance among years $\left(F_{2,98}=0.98, \mathrm{p}>35\right)$ or interaction between year and area $\left(F_{2,98}=0.01, \mathrm{p}>0.9\right)$.

The density of small individuals varied significantly among sites within areas (Table 4), but there were no

Table 2. ANOVA of the number of juveniles per unit area. Data $(x+1)^{1 / 2}$ transformed to meet assumption of homogeneity of variances

\begin{tabular}{|c|c|c|c|c|c|}
\hline Source & $\mathrm{df}$ & MS & $F$ & $\mathrm{p}$ & $F$-ratio vs \\
\hline Height on shore & 2 & 0.105 & 6.27 & $<0.01$ & Height on shore $\times$ Site \\
\hline Site & 5 & 0.009 & 0.36 & $>0.8$ & Plot (Height on shore, Site) \\
\hline Height on shore $\times$ Site & 10 & 0.017 & 0.64 & $>0.7$ & Plot (Height on shore, Site) \\
\hline Plot (Height on shore, Site) & 36 & 0.026 & 0.88 & $>0.6$ & Square (Height on shore, Site, Plot) \\
\hline Square (Height on shore, Site, Plot) & 108 & 0.030 & 2.34 & $<0.0001$ & Residual \\
\hline \multirow[t]{2}{*}{ Residual } & 810 & 0.013 & & & \\
\hline & $\mathrm{df}$ & C & & $\mathrm{p}$ & . \\
\hline Cochran's C-test & 162,5 & 0.016 & & $>0.05$ & \\
\hline
\end{tabular}




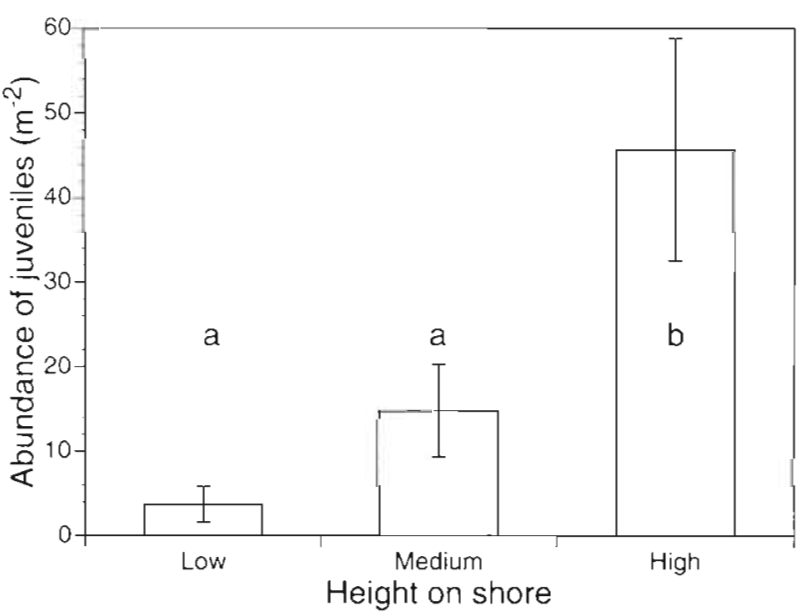

Fig. 2. Ascophyllum nodosum. Mean number of juveniles $\mathrm{m}^{-2}$ at different heights on the shore at the Isle of Man. $a, b$ significant groups (SNK, $p<0.05$ ). Error bars are \pm SE

significant interactions or effects of the main factors Year and Area (Table 4), and the overall mean was 81 small individuals $\mathrm{m}^{-2}$. The result was similar for the total density (Table 4), and the overall mean number of individuals was $161 \mathrm{~m}^{-2}$. However, for large individuals no significant variation in the density was found on the smallest spatial scale, but the density varied significantly between areas (Table 4). The mean density was larger at Tjärnö $\left(99 \mathrm{~m}^{-2}\right)$ than at the Isle of Man $\left(76 \mathrm{~m}^{-2}\right)$. Post hoc pooling of the non significant interaction terms Year $\times$ Site (Area) (all dependent variables; Table 4) revealed a significant variation among years in the density of large plants $\left(F_{3,108}=3.23, \mathrm{p}<\right.$ 0.05 ) and the mean densities were $104,85,77$, and $83 \mathrm{~m}^{-2}$ for the years 1992 to 1995 . The pooling procedure did not alter other conclusions from Table 4 .

\section{Temporal and spatial variation in the size of reproductive individuals}

A preliminary test showed that the interaction term Year $\times$ Site (Area) was not significant in any of the 2 cases and the term was eliminated and pooled. No temporal variation in the 2 variables was found in the experiments, but both the length and the size of individuals showed a significant variation between squares within year, area and site and also between sites within areas (Table 5). Individuals at Isle of Man were longer than those at Tjärnö, with means of 96 and $73 \mathrm{~cm}$ respectively, but no difference was found in the mean size of individuals, and the overall geometric mean was $75 \mathrm{~g}$ dry mass.

\section{Eggs per conceptacle}

Significant differences in the number of eggs per conceptacle were found among receptacles within an individual, but there were no differences among individuals (Table 6). The mean number was 685 eggs per conceptacle.

\section{Conceptacles per receptacle}

The variation between individuals in the number of conceptacles per receptacle was analysed with an ANCOVA, in which receptacle size was used as a covariate. That is, we compared individuals when the possible effects of receptacle size were taken away. The ANCOVA showed no significant interaction, satisfying the assumption of homogeneity of slopes (Table 7). No significant difference in the number of conceptacles per receptacle was found (Table 7 ) and the mean number of conceptacles per receptacle was estimated to be 100. A significant effect of the covariate indicated a relationship between receptacle mass and and conceptacle number. This was further analysed with a linear regression which showed a significant relationship between conceptacle number and receptacle mass ( $\mathrm{p}<$ $0.0001, \mathrm{r}^{2}=0.55, \mathrm{n}=30$ ). A similar relationship with receptacle mass was also found using the estimated number of eggs per conceptacle times the number of conceptacles per receptacle as the dependent variable $\left(p<0.0001, r^{2}=0.53, n=30\right)$. Given the figures above, there will be $7 \times 10^{4}$ eggs in a mean sized receptacle.

\section{DISCUSSION}

Significant variation in juvenile abundance was found on the scale of 0.1 to $1.5 \mathrm{~m}$ and on the scale of 2 to $30 \mathrm{~m}$. However, the large variance component of the

Table 3. ANOVA of the number of new juveniles per unit area. Data $(x)^{1 / 3}$ transformed to meet assumption of homogeneity of variances

\begin{tabular}{|lrcccl|}
\hline Source & df & MS & $F$ & p & F-ratiovs \\
\hline Year & 2 & 0.380 & 1.48 & $>0.25$ & Year $\times$ Site (Area) \\
Area & 1 & 0.279 & 0.39 & $>0.55$ & Site (Area) \\
Site (Area) & 4 & 0.710 & 1.78 & $>0.10$ & Residua] \\
Year $\times$ Area & 2 & 0.005 & 0.02 & $>0.90$ & Year $\times$ Site (Area) \\
Year $\times$ Site (Area) & 8 & 0.258 & 0.64 & $>0.70$ & Residual \\
Residual & 90 & 0.399 & & & \\
& & & & & \\
& df & $C$ & & p & \\
\hline Cochran's C-test & 18,5 & 0.16 & & $>0.05$ & \\
& & & & &
\end{tabular}


Table 4. ANOVA of the density of small, large, and all individuals. Data $(x+1)^{1 / 2}$ transformed to meet assumption of homogenerty of variances

\begin{tabular}{|c|c|c|c|c|c|c|c|c|c|c|c|}
\hline \multirow[t]{2}{*}{ Source } & \multirow[t]{2}{*}{ df } & \multicolumn{3}{|c|}{ Small } & \multicolumn{3}{|c|}{ Large } & \multicolumn{3}{|c|}{ All } & \multirow[t]{2}{*}{$F$-ratio vs } \\
\hline & & MS & $F$ & $\mathrm{p}$ & MS & $F$ & $\mathrm{p}$ & MS & $F$ & $p$ & \\
\hline Year & 3 & 1.537 & 3.08 & $>0.05$ & 0.531 & 2.75 & $>0.05$ & 0.401 & 0.71 & $>0.55$ & Year $\times$ Site (Area) \\
\hline Area & 1 & 1.265 & 0.62 & $>0.45$ & 2.432 & 9.76 & $<0.05$ & 0.422 & 0.25 & $>0.60$ & Site (Area) \\
\hline Site (Area) & 4 & 2.035 & 2.86 & $<0.05$ & 0.249 & 1.55 & $>0.15$ & 1.674 & 3.30 & $<0.05$ & Residual \\
\hline Year $\times$ Area & 3 & 0.877 & 1.76 & $>0.20$ & 0.196 & 1.02 & $>0.40$ & 0.138 & 0.24 & $>0.85$ & Year $\times$ Site (Area) \\
\hline Year $\times$ Site (Area) & 12 & 0.499 & 0.70 & $>0.70$ & 0.193 & 1.20 & $>0.25$ & 0.566 & 1.12 & $>0.35$ & Residual \\
\hline \multirow[t]{2}{*}{ Residual } & 96 & 0.712 & & & 0.161 & & & 0.507 & & & \\
\hline & $\mathrm{df}$ & C & & $\mathrm{p}$ & $C$ & & $\mathrm{p}$ & $C$ & & $p$ & \\
\hline Cochran's C-test & 24,4 & 0.17 & & $>0.05$ & 0.12 & & $>0.05$ & 0.15 & & $>0.05$ & \\
\hline
\end{tabular}

Table 5. ANOVA of the estimated dry mass of large individuals and the length of large individuals. Data of dry mass log( $x$ ) transformed to meet assumption of homogeneity of variances

\begin{tabular}{|c|c|c|c|c|c|c|c|c|}
\hline \multirow[t]{2}{*}{ Source } & \multirow[t]{2}{*}{$\mathrm{df}$} & \multicolumn{3}{|c|}{ Dry mass } & \multicolumn{3}{|c|}{ Length } & \multirow[t]{2}{*}{$F$-ratio vs } \\
\hline & & MS & $F$ & $\mathrm{p}$ & MS & $F$ & $p$ & \\
\hline Year & 3 & 1.155 & 0.55 & $>0.60$ & 394.5 & 0.21 & $>0.85$ & Square (Year, Area, Site) \\
\hline Area & 1 & 41.823 & 3.75 & $>0.10$ & 98397.1 & 17.70 & $<0.05$ & Site (Area) \\
\hline Year $\times$ Area & 3 & 4.924 & 2.36 & $>0.05$ & 720.9 & 0.39 & $>0.75$ & Square (Year, Area, Site) \\
\hline Site (Area) & 4 & 11.145 & 5.34 & $<0.001$ & 5559.0 & 2.98 & $<0.05$ & Square (Year, Area, Site) \\
\hline Square (Year $\times$ Area (Site)) & 132 & 2.087 & 1.39 & $<0.01$ & 1863.4 & 2.37 & $<0.0001$ & Residual \\
\hline \multirow[t]{2}{*}{ Residual } & 576 & 1.501 & & & 787.5 & & & \\
\hline & $\mathrm{df}$ & $C$ & & $\mathrm{p}$ & C & & $\mathrm{p}$ & \\
\hline Cochran's C-test & 24,5 & 0.15 & & $>0.05$ & 0.13 & & $>0.05$ & \\
\hline
\end{tabular}

residual also suggests a large variation on the scale 0.05 to $0.15 \mathrm{~m}$. The patchy distribution of macrorecruits may be seen from qualitative observation, but the present study quantified important spatial scales. Mechanisms causing this pattern cannot be determined from observation experiments. Possible mortality factors that also vary on these scales have to be identified before their effect on recruitment can be studied in manipulative field experiments incorporating important spatiai scales. Cervin \& Aberg (1997) included sites and plots, on the same scale as in the present study, in a field experiment on the effect of littorinid grazers on the mortality of 1 wk old Ascophyllum nodosum zygotes. No significant effect of the grazer was found, but significant differences were found between plots within sites and treatment (grazer absent or present). The study showed that heterogeneity of $A$. nodosum recruits on a scale from 2 to $30 \mathrm{~m}$ can be found as early as the microrecruit stage (Cervin \& Åberg 1997). However, the experiment could not differentiate between treatments on the smaller scale and, with the knowledge gained from the present study, the design should have been different, i.e. with a better focus on the smaller scales. Lazo et al. (1994) showed a significant effect of grazers on the recruitment of $A$. nodosum, but some mortality was also found in the absence of grazers, which they suggest was due to density dependent effects. Although spatial variation was not investigated, the mean numbers they give have large standard deviations, indirectly indicating spatial variation both in the presence and absence of grazers. Wave action can dramatically increase the mortality of zygotes, but is probably more important at a larger scale (Vadas et al. 1990). In the present study we did not find differences between sites, but the study was restricted to sheltered shores. If both sheltered and more exposed shores were included it is most likely that differences in abundance of juveniles on the scale $10^{2}$ to $10^{3} \mathrm{~m}$ would be found. However, effects of waves and currents within sheltered shores cannot be ruled out, since the variations in hydrodynamic conditions on small scales are not well known. Canopy removal has been shown to increase the recruitment of A. nodosum (e.g. Vadas et al. 1992, Jenkins 1995) and 
Table 6. ANOVA of the number of eggs per conceptacle

\begin{tabular}{|lrrrl|}
\hline Source & df & MS & $F$ & $\mathrm{p}$ \\
\hline Individual & 9 & 338343 & 1.65 & $>0.15$ \\
Receptacle (Individual) & 20 & 205312 & 6.18 & $<0.0001$ \\
Residual & 120 & 33238 & & \\
& df & $C$ & & $\mathrm{p}$ \\
\hline Cochran's C-test & 30,4 & 0.16 & $>0.01$ \\
\hline
\end{tabular}

Table 7 ANCOVA of the number of conceptacles per receptacle. Receptacle mass is used as covariate

\begin{tabular}{|lrrrc|}
\hline Source & df & \multicolumn{1}{c}{ MS } & \multicolumn{1}{c|}{$F$} & p \\
\hline Individual & 9 & 380.19 & 1.42 & $>0.25$ \\
Receptacle mass & 1 & 5487.01 & 20.49 & $<0.001$ \\
Individual $\times$ Receptacle mass & 9 & 81.17 & 0.30 & $>0.90$ \\
Residual & 10 & 267.83 & & \\
\hline
\end{tabular}

sweeping has been suggested as the factor inhibiting recruitment in dense stands (Vadas et al. 1992), but Jenkins (1995) suggested an alternative explanation. He found that the red algal turf degenerated after canopy removal and the resulting mosaic of algae, silt, and bare rock may have promoted recruitment. The importance of microhabitat variation for juvenile abundance has also been shown for Pelvetia fastigiata (Brawley \& Johnson 1991). Brawley \& Johnson (1991) showed that the survival of $P$. fastigiata embryos varied among microhabitats (canopy present, red algal turf, exposed) and the survival pattern reflected the microhabitat temperatures during the experiments. The present study was restricted to plots where adult plants were present, but the small scale variation in adult size may indicate small scale differences in the canopy that may be important for the small scale variation in juvenile abundance.

The lack of difference in abundance of juveniles between areas is interesting. Large differences in the physical and biological environment can be found between Tjärnö and the Isle of Man, but the pattern in abundance of Ascophyllum nodosum juveniles is similar. The limpet Patella vulgata is common in the $A$. nodosum zone on the Isle of Man, but not so abundant as on more exposed shores (Hawkins et al. 1992). The effect of limpets is easily observed; we never found juveniles on substratum grazed by limpets, but recruits are often found on their shells. That limpets reduce the number $A$. nodosum juveniles on bare rock has also been demonstrated with controlled experiments on sheltered Manx shores (Jenkins 1995). P. vulgata is extremely rare on the Swedish west coast and was not found at Tjärno during the 3 yr study. That is, the pattern of juvenile abundance at Tjärnö cannot be explained by grazing of this species. However, crustacean mesoherbivores may be important for establishing the small scale variation in juvenile abundance in Sweden (Cervin \& Aberg 1997).

Several papers have suggested that recruitment in Ascophyllum nodosum is a stochastic event (e.g. Vadas et al. 1990, Åberg 1992a, Lazo et al. 1994). However, the present study suggests no differences in recruitment among the years 1992 to 1995 . The variation between years was small compared to that at small spatial scales. Years with a long period of ice cover have been correlated with high mortality of small $A$. nodosum plants (Aberg 1992a, b), but none of the 3 years in the present study was an extreme ice year at Tjärnö. We expect that much lower values can be found in some years at Tjärnö. Three years is also a rather short period for this long lived species (Åberg $1992 b)$ and significant temporal variation may be found on a larger time scale.

Several authors have remarked upon the low recruitment rate in Ascophyllum nodosum (e.g. Baardseth 1970, Sundene 1973, Vadas et al. 1990, Lazo et al. 1994). But is it really low? Yes, in some areas in Maine this seems to be true, as no recruits were found during a 20 yr period (Vadas et al. 1990). On the other hand the rates in the present study are not low if they are related to the vital rates of A. nodosum. Aberg (1992a) showed that during ice free years in populations on the Swedish west coast very few recruits $\mathrm{m}^{-2}$ were needed to get an increase in population size. Preliminary analyses of the population growth at the Isle of Man show that about 5 recruits $\mathrm{m}^{-2}$ are all that is needed to get a positive growth. However, if the number of recruits is related to the large investment of reproductive biomass in A. nodosum (Cousens 1986, Mathieson \& Guo 1992, Ảberg 1996) recruitment success may be regarded as low, but a low cost of reproduction for large individuals has been indicated (Åberg 1996). Of the other variables studied, only the density of large individuals showed significant temporal variation, but there are no previous studies from which we can suggest an explanation for this.

More juveniles were found high in the intertidal, which agrees with earlier qualitative observations. Jenkins (1995) speculated that this pattern could be due to several factors such as lower densities of limpets, more bare rock and more light due to smaller adult plants. To this we would also like to add the dispersal pattern of gametes. Gametes are released during low tide. When the water comes back the main current will be upwards suggesting higher densities of gametes higher up on the shore. Although eggs are heavy and may not disperse more than a few meters, 
the sperm are viable during the first $15 \mathrm{~h}$ (authors pers. obs.), so large densities of sperm may accumulate higher up on the shore, increasing fertilization success.

To quantify the fertility of an organism is important for demographic analyses. Here we follow the usage of many demographers (see Caswell 1989) and use fertility to describe actual reproductive performance and fecundity to denote the physiological maximum reproductive output. Chapman (1995) in his review of fucoid ecology stated that the first step in a demographic budget is to determine the egg output of a stand. In theory this is not needed. If fertility can be assessed for stage classes used in the demographic model no estimate of fecundity is needed. However, this has not been done for any macroalgae and indirect measures are needed: to correlate fecundity with fertility is the usual procedure. Estimates of egg output are a good start. Even in cases where the transition probabilities from spore or egg to visible plant are known (e.g. Chapman 1993), the fertility estimates are still indirect. Chapman (1995) correctly criticized the fertility measures used in an earlier study of Ascophyllum nodosum (Åberg 1992a) because reproductive biomass of an individual was used as a fecundity estimate, which in turn was correlated to fertility (number of new recruits found in the field). However, the figures in the present paper show no significant variation between individuals in the number of eggs per conceptacle and in the number of conceptacles per receptacle. Furthermore, it was found that the receptacle mass is correlated to the number of eggs per receptacle and this relation explained more of the variation than a similar correlation could for Fucus spiralis (Robertson 1987). The relationship will, however, not influence the correlation between fecundity and fertility because there is no difference in the mean size of receptacles of large individuals ( $\AA$ berg 1996). That is, with the knowledge we have thus far, the number of receptacles per individual (or the individual's dry mass) will be as good or bad as egg production to indirectly estimate fertility.

Using the estimated number of receptacles per plant dry mass in $\AA$ berg (1996) and the estimate in this study of $7 \times 10^{4}$ eggs per receptacle, a small individual of $15 \mathrm{~g}$ dry mass will produce $1 \times 10^{7}$ eggs per reproductive season ( $\sim 2$ wh every year), and a mean sized individual will produce $6 \times 10^{7}$ eggs per reproductive season. Individuals larger than $1 \mathrm{~kg}$ dry mass have been found in the field and will have an estimated egg production of almost $10^{9}$ eggs per reproductive season. The potential egg rain (cf. seed rain used for terrestrial plants) will be $2.5 \times 10^{9}$ eggs $\mathrm{m}^{-2}$ per reproductive season, using the density of large individuals, the mean number of eggs from a mean sized individual from the present study and a sex ratio of 1:1 ( $\AA$ berg 1989). This figure is higher than other estimates for fucoids, e.g.
$1.5 \times 10^{7}$ eggs m $\mathrm{m}^{-2} \mathrm{yr}^{-1}$ for Fucus distichus (Ang 1991), $3 \times 10^{8}$ eggs $\mathrm{m}^{-2}$ for Fucus spiralis in the month of September (Robertson 1987) and $2 \times 10^{6}$ eggs $\mathrm{m}^{-2} \mathrm{yr}^{-1}$ for Sargassum sinclarii (Schiel 1988). The proportion of eggs that survive and become $1.5 \mathrm{yr}$ old macrorecruits, given the figures in the present paper, is estimated to be $2 \times 10^{-8}$. Both the production of eggs and their transition to macrorecruits are more like those estimated for kelp spores (Chapman 1984). However, the present projections should be regarded as rough estimates giving ideas of the actual order of magnitude.

The recruitment of Ascophyllum nodosum clearly varies on small spatial scales, suggesting that demographic analyses should also include these scales. However, adult mortality may vary on other scales and future demographic studies should, if practically possible, include several spatial scales

Acknowledgements. We are grateful to the staff and students at Port Erin Marine Laboratory and Tjärnö Marine Biological Laboratory for their help and hospitality. This study was supported by the Swedish Natural Science Research Counci through contract B-BU 9949-302 to P.A. The Royal Swedish Academy of Science, through the foundation of Hierta-Retzius, and the foundations of Helge Ax:son Johnson, Knut \& Alice Wallenberg. Wilhelm \& Martina Lundgren and Kapten Carl Stenholm provided additional support

\section{LITERATURE CITED}

Åberg P (1989) Distinguishing between genetic individuals in Ascophyllum nodosum populations on the Swedish west coast. Br Phycol J 24:183-190

Aberg P (1990) Measuring size and choosing category size for a transition matrix study of the seaweed Ascophyllum nodosum. Mar Ecol Prog Ser 63:281-287

Åberg P (1992a) A demographic study of two populations of the seaweed Ascophyllum nodosum. Ecology 73: $1473-1487$

Åberg P (1992b) Size based demography of the seaweed Ascophyllum nodosum in stochastic environments. Ecology 73:1488-1501

Aberg P (1996) Patterns of reproductive effort in the brown alga Ascophyllum nodosum. Mar Ecol Prog Ser 138: $199-207$

Ang PO (1991) Natural dynamics of a Fucus distichus (Phaeophyceae, Fucales) population. Mar Ecol Prog Ser 78:71-85

Baardseth E (1970) Synopsis of biological data on Ascophyllum nodosum (Linneaus) Le Jolis. FAO Fish Synop 38: $1-40$

Brawley SH, Johnson LE (1991) Survival of fucoid embryos in the intertidal zone depends upon developmental stage and microhabitat. J Phycol 27:179-186

Caswell H (1989) Matrix population models. Sinauer, Sunderland, MA

Cervin G, Aberg P (1997) Do Littorina spp. affect the survival of Ascophyllum nodosum germlings? J Exp Mar Biol Ecol 218:35-47

Chapman ARO (1984) Reproduction, recruitment and mortality in two species of Laminaria in southwest Nova Scotia. J Exp Mar Biol Ecol 78:99-109

Chapman ARO (1993) 'Hard' data for matrix modelling of 
Laminaria digitata (Laminariales, Phaeophyta) populations. Hydrobiologia 260/261:263-267

Chapman ARO (1995) Functional ecology of fucoid algae: twenty-three years of progress. Phycologia 34:1-32

Cousens R (1986) Quantitative reproduction and reproductive effort by stands of the brown alga Ascophyllum nodosum (L.) Le Jolis in south-eastern Canada. Estuar Coast Shelf Sci 22:495-507

Hawkins SJ, Hartnoll RG, Kain JM, Norton TA (1992) Plantanimal interactions on hard substrata in the north-east Atlantic. In: John DM, Hawkins SJ, Price JH (eds) Plantanimal interactions in the marine benthos. Syst Assoc Spec Vol 46:1-32

Jenkins SR (1995) The ecology of sheltered, canopy dominated shores. PhD thesis, University of Liverpool

Johannesson K (1989) The bare zone of Swedish rocky shores: why is it there? Oikos 54:77-86

Lazo L, Markham JH, Chapman ARO (1994) Herbivory and harvesting: effects on sexual recruitment and vegetative modules of Ascophyllum nodosum. Ophelia 40:95-113

Levin SA (1992) The problem of pattern and scale in ecology. Ecology 73:1943-1967

Mathieson AC, Guo Z (1992) Patterns of fucoid reproductive biomass allocation. Br Phycol J 27:271-292

Morrisey DJ, Howitt L, Underwood AJ, Stark JS (1992) Spatial variation in soft-sediment benthos. Mar Ecol Prog Ser 81 $197-204$

Pavia H, Åberg P (1996) Spatial variation in polyphenolic content of Ascophyllum nodosum. Hydrobiologia 326/327: 199-203

Peckol P, Harlin MM, Krumscheid P (1988) Physiological and population ecology of intertidal and subtidal Ascophyllum nodosum (Phaeophyta). J Phycol 24:192-198

Robertson B (1987) Reproductive ecology and canopy structure of Fucus spiralis L. Bot Mar 30:475-482

Rönnberg O, Ruokolahti C (1986) Seasonal variation of algal epiphytes and phenolic content of Fucus vesiculosus in a northern Baltic archipelago. Ann Bot Fenn 23:317-323

Schiel DR (1988) Algal interactions on subtidal reefs in northern New Zealand: a review. NZ J Mar Freshwat Res 22: $481-489$

Editorial responsibility: Anthony Underwood (Contributing Editor), Sydney, Australia
Steinberg PD, Edyvan K, DeNys R, Birdsey R, Van Alten IA (1991) Lack of avoidance of phenolic-rich brown algae by tropical herbivorous fishes. Mar Biol 109:335-343

Sundene O (1973) Growth and reproduction in Ascophyllum nodosum (Phaeophyceae). Norw J Bot 20:249-255

Targett NM, Coen LD, Boettcher AA, Tanner CE (1992) Biogeographic comparisons of marine algal polyphenolics: evidence against a latitudinal trend. Oecologia 89 $464-470$

Tuomi J, Ilvessalo $\mathrm{H}$, Niemelä $\mathrm{P}$, Sirén $\mathrm{S}$, Jormalainen $\mathrm{V}$ (1989) Within-plant variation in phenolic content and toughness of the brown alga Fucus vesıculosus L. Bot Mar 32:505-509

Underwood AJ (1985) Physical factors and biological interactions: the necessity and nature of ecological experiments In: Moore PG, Seed R (eds) The ecology of rocky coasts Hodder and Stoughton, London, p 372-390

Underwood AJ (1991) The logic of ecological experiments: a case history from studies of the distribution of macro-algae on rocky intertidal shores. J Mar Biol Assoc UK 71:841-866

Underwood AJ (1997) Experiments in ecology: their logical design and interpretation using analysis of variance. Cambridge University Press, Cambridge

Underwood AJ, Denley EJ (1984) Paradigms, explanations and generalizations in models for the structure of intertidal communities on rocky shores. In: Strong D. Simberloff $\mathrm{L}$, Abele $\mathrm{G}$, Thistle AB (eds) Ecological communities: conceptual issues and the evidence. Princeton University Press, Princeton, p 151-180

Vadas RL, Johnson S, Norton TA (1992) Recruitment and mortality of early post-settlement stages of benthic algae. $\mathrm{Br}$ Phycol J 27:331-3.51

Vadas RL, Wright WA, Miller SL (1990) Recruitment of Ascophyllum nodosum: wave action as a source of mortality. Mar Ecol Prog Ser 61:263-272

Van Alstyne KL, Paul VJ (1990) The biogeography of polyphenolic compounds in marine macroalgae: temperate brown algal defenses deter feeding by tropical herbivorous fishes. Oecologia 84:158-163

Winer BJ, Brown DR, Michels KM (1991) Statistical principles in experimental design. McGraw-Hill, New York

Submitted: February 10, 1997; Accepted: July 22, 1997

Proofs recelved from author(s): October 9, 1997 